\title{
Enamel print pattern in Deutero-Malay sub race based on extracted female permanent maxillary central incisors
}

\author{
Tan Kien Huat ${ }^{1 *}$, Murnisari Dardjan¹, Winny Yohana ${ }^{1}$ \\ ${ }^{1}$ Department of Oral Biology, Faculty of Dentistry Universitas Padjadjaran, Indonesia
}

\begin{abstract}
Introduction: Enamel print pattern is a series of lines representing the enamel rod ends pattern. These lines are seen running in varying directions creating distinct sub-patterns; thus, enamel print pattern allows for personal identification. This study was aimed to investigate the enamel print pattern in Deutero-Malay sub race based on extracted female permanent maxillary central incisors. Methods: This study used descriptive-analytic methods. The population of this study was Deutero-Malay sub-race female individuals who came to Batu Pahat Dental Surgery, Johor, Malaysia. The samples were 31 post-extracted permanent maxillary central incisors teeth in good condition, with closed root apex. Photomicrographs and a digital photo of samples were taken, then analysed using SourceAFIS-1.7.0 biometric software. Results: The results showed that there was a combination of few sub-patterns. The most prominent sub-pattern was linear-branched $(21.36 \%)$, in decreasing orders of prominence were the wavy-branched (19.42\%), wavy-unbranched $(16.50 \%)$ and linear-unbranched $(15.53 \%)$. The less common sub-patterns were the whorl-open $(9.71 \%)$, loop $(6.80 \%)$, whorl-closed $(5.83 \%)$ and stem-like $(4.85 \%)$. Conclusion: The enamel print pattern in every central incisor has no similarity; hence can be a possible tool for personal identification.
\end{abstract}

Keywords: Enamel print pattern, Deutero-Malay, maxillary central incisors.

p-ISSN: 1979-0201; e-ISSN: 2549-6212; Available from: http://jurnal.unpad.ac.id/pjd/article/view/23959

DOI: 10.24198/pjd.vol31no3.23959

Submission: Oct 18, 2019; Accepted: Mar 10, 2020; Published online: Mar 31, 2020

\section{INTRODUCTION}

Human Identification, an integral part of forensic science, is prone to be the most challenging subjects that man has been confronted with. ${ }^{1}$ Personal identification is becoming very crucial and its usually achieved by use of passwords, photograph, iris pattern, fingerprints and DNA analysis. ${ }^{2}$ There are variety of methods that have been used for personal identification such as rugoscopy, cheiloscopy, bite marks, radiographs, photographic study and molecular methods. ${ }^{3}$ Nevertheless, these identification methods commonly fail or certain limitations.

It may not be efficient when bodies are decomposed, burned or when there is only small 
fragments of calcified tissues are left. In the recent years, dental hard tissues gain importance in identification based on the deceased condition. Hence, the use of teeth as dental evidence is the first and foremost method of choice in establishing the identity of badly burned, traumatized, decomposed, and skeletonized remains. ${ }^{2}$ Ameloglyphics is the study of enamel rod end patterns on tooth surface and these enamel rod ends will form specific enamel print patterns on the tooth surface which is highly unique for every tooth. ${ }^{4}$

The enamel consists primary of inorganic material (96\%) and merely a small amount of organic substance and water (4\%). The inorganic material of the enamel is hydroxyapatite. In cross section, the hydroxyapatite crystals are in a rod shape with hexagon base. The crystals are arrange to form enamel rods or enamel prisms. The core of the crystals are rich in $\mathrm{Mg}$ and carbonate. ${ }^{5}$ This superior organization and mineralization properties provide the enamel its outstanding physical properties, making it the hardest tissue in the vertebrate body. ${ }^{4}$

About $300 \mathrm{BC}$, the second migration came Deutero-Malay which then spread to become the people of Aceh, Jawa, Sunda, Minangkabau, Riau, Bugis, and some parts of Tamiang, Melayu Deli, Jambi, Bengkulu, Palembang, Makassar, Bali and Sasak. Deutero Malay subrace is the mixture of Proto Malay subrace with Mongoloid. ${ }^{6}$ The purpose of the research is to investigate the enamel print pattern in Deutero Malay subrace based on extracted female permanent maxillary central incisors. This study was aimed to investigate the enamel print pattern in Deutero-Malay sub race based on extracted female permanent maxillary central incisors.

\section{METHODS}

This research was descriptive analytic methods, conducted in the period of November-December 2017. The population of this study was DeuteroMalay sub race female individuals who come to Batu Pahat Dental Surgery, Johor, Malaysia. The samples choosen was post extracted permanent maxillary central incisors teeth, and good condition teeth with close root apex. The selected teeth were cleaned with distilled water to remove blood and stains. It is then stored in a container which contains 10\% formalin for 1 week. Formalin act as disinfectant and antiseptic for post extracted teeth. Next, the teeth were transferred to a container of $0.9 \% \mathrm{NaCl}$ solution and stored at room temperature. The function of $\mathrm{NaCl}$ is to prevent post-extraction teeth from dehydration. Every once in 2 week time, the solution was replaced by a new solution until research was carried out.

The teeth were clean with distilled water and then dried before placing the teeth to the microscope. The crown was divided into 3 regions partly incisal third, middle third and cervical third. Each dimension was equivalent to each other and was determined by using compasses. The tooth surface being observed is the middle
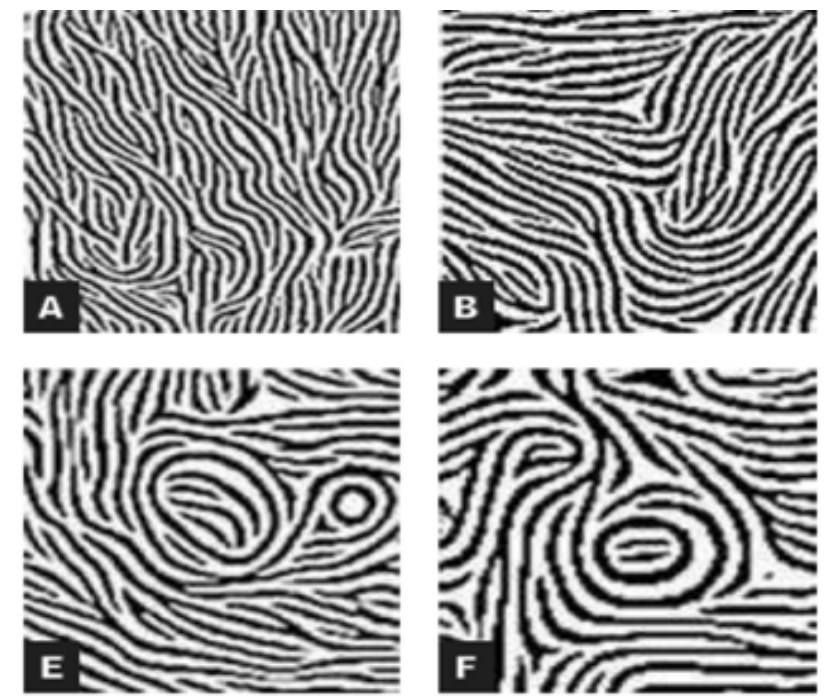
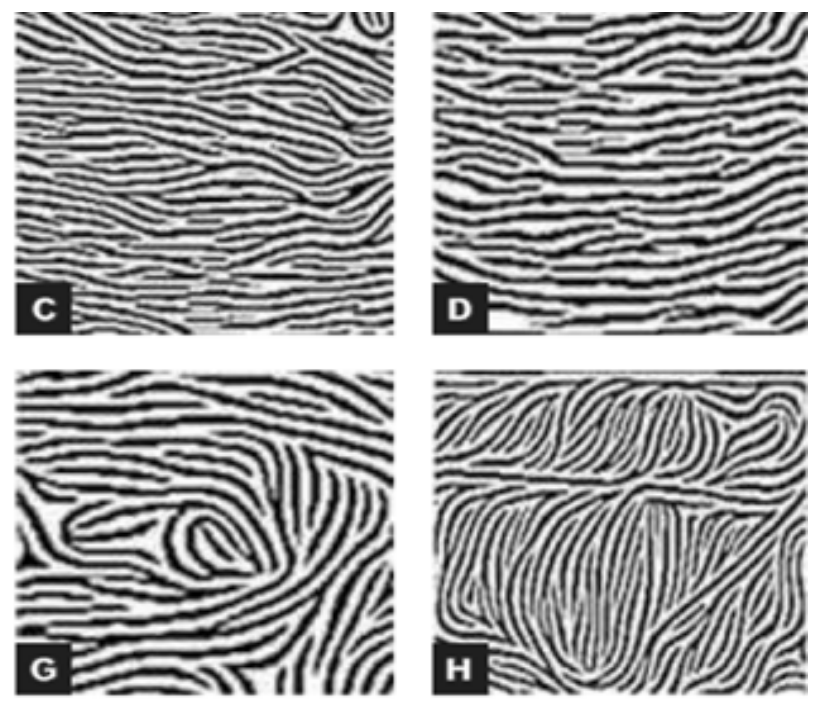

Figure 1. Eight distinct sub-patterns observed in tooth print where: A. Wavy-branched; B. Wavy-unbranched; C. linearbranched; D. Linear-unbranched; E. Whorl-open; F. Whorl-closed; G. Loop; H. Stem-like. ${ }^{3}$ 


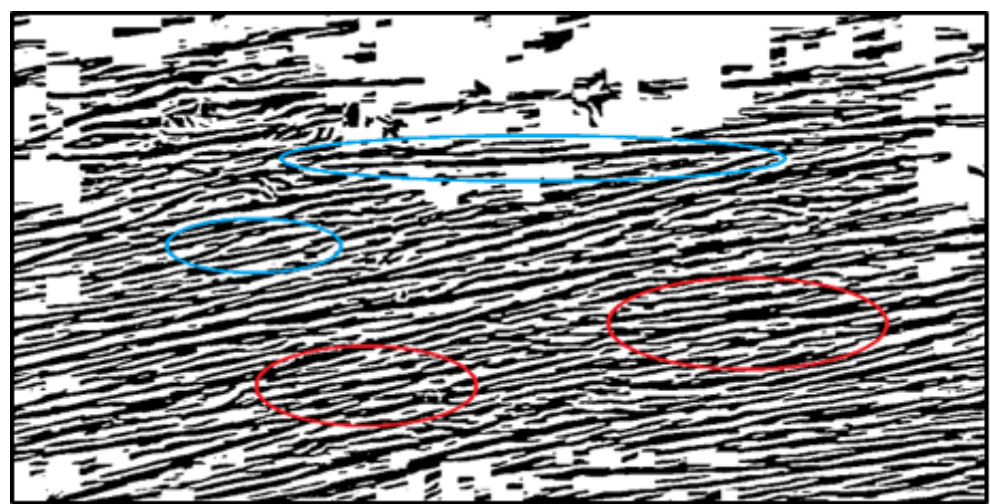

Figure 2. Photomicrograph image of one of the samples where the blue circle is linear-unbranched pattern and red circle is linear-branched pattern.

third of the labial surface. The photomicrograph of the samples were taken with Nikon SMZ800 zoom stereomicroscope which were connected to DSLR Nikon D3300 camera. The photomicrograph was subjected to biometric analysis by using SourceAFIS-1.7.0 biometric-based software and the image size is $1 \mathrm{cmX} 1 \mathrm{~cm}$. The software will then compare the similarity and differences of all enamel print patterns collected. The ethical exemption No:1115/UN6.C10/PN/2017 from Faculty of Medicine of Universitas Padjadjaran Bandung which was issued on the $21^{\text {st }}$ of November 2017.

\section{RESULTS}

To eliminate inter-examiner variability, all the analyses were done by same examiner. To test the intra-examiner reproducibility a random sample of 10 maxillary central incisors were reexamined after an interval of 2 weeks. Each time the examiner examine the samples, the enamel print patterns observed were the same. For example, in sample A, wavy-branched pattern were observed.

Each enamel print pattern obtained from the samples composed of series of lines. These lines represent series of enamel rod ends pattern. The lines were seen running in varying directions thus create distinct sub-patterns of enamel print. The software will then recognized the enamel print pattern in the form of a series of black lines that run in different directions against a white background. The enamel prints patterns will be classified into 8 distinct sub-patterns namely wavy-branched, wavy-unbranched, linearbranched, linear-unbranched, whorl-open, whorlclosed, loop and stem-like. The software uses certain points called minutae for identification of each pattern. These minutae will be used by the software to compare the similarity and differences of all samples. The different subpatterns of enamel print pattern were obviously
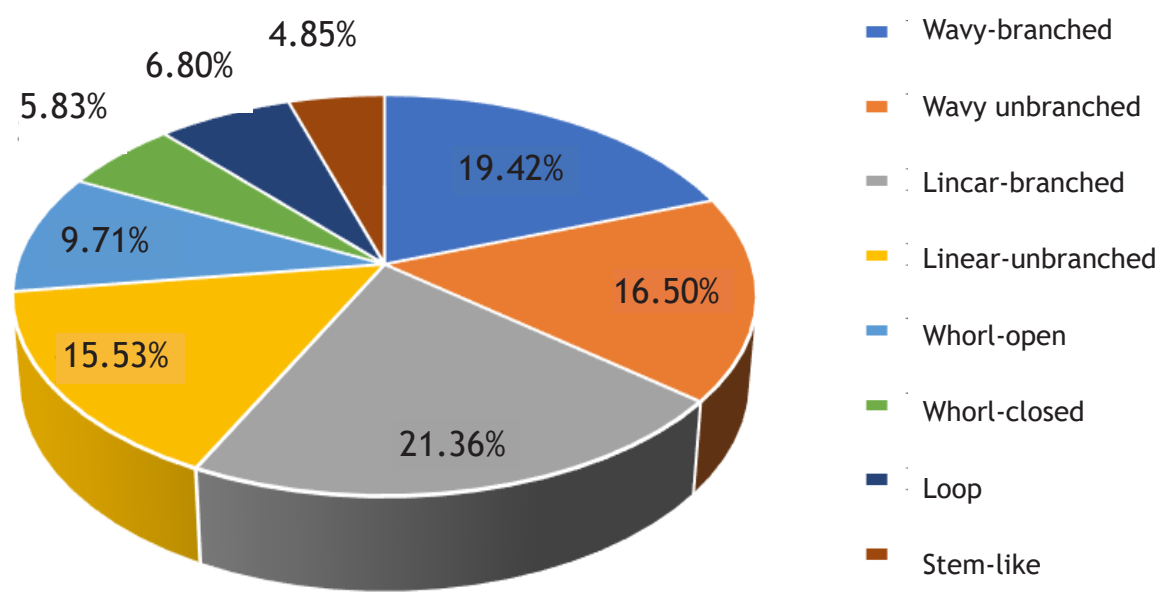

Figure 3. Frequency distribution of sub-patterns from collected sample 
observed with varying degrees of predominance. The percentage of various sub-patterns of enamel print was shown in Figure 3.

\section{DISCUSSION}

Recently, ameloglyphics have been proposed and considered as a highly reliable biometric based procedure for personal identification. ${ }^{7}$ Formation of enamel is a highly organized process in which the ameloblasts lay down the enamel rods which run the whole length of enamel in an undulating and intertwining path. This will form a specific pattern on the tooth surface known as enamel print patterns and is highly unique for each tooth in an individual. ${ }^{8}$

The technique used in this research is photomicrograph of the enamel print pattern. With this technique, it has been recorded that every samples collected in this study have different subpatterns of enamel print patterns with minimum of at least two sub-patterns. There are 8 distinct sub patterns recorded which are the wavy-branched, wavy-unbranched, linear-branched, linearunbranched, whorl-open, whorl-closed, loop and stem-like. wavy-branched and wavy-unbranched are the curve, wavy-like patterns with branching or without branching respectively. Linearbranched and linear-unbranched are the straight lines or almost straight patterns with branching or without branching respectively. Whorl-open and whorl-closed sub-patterns are similar to coiled shape with open borders or closed borders respectively. Loop sub-pattern may resemblance a loophole shape while stem-like sub-pattern akin to a stem shape.

In this research, the most common enamel print pattern observed was the linear branched $(21.36 \%)$, which mean among all the samples collected in this research, this pattern occurred the most among every other patterns. In decreasing number of prominence were the wavy-branched (19.42\%), wavy-unbranched $(16.50 \%)$ and linearunbranched $(15.53 \%)$. The less common subpatternswere the whorl-open (9.71\%), loop (6.80\%), whorl-closed $(5.83 \%)$ and stem-like $(4.85 \%)$.

A study done by Ramenzoni et al. ${ }^{9}$ showed that enamel print pattern could be examined and photographed without special preparation from extracted central incisors. The enamel print pattern were then observed with a binocular microscope (magnification of 20x) and light shinning obliquely on the tooth (optic fiber-Fiber Light). From cervical to the mid coronal regions
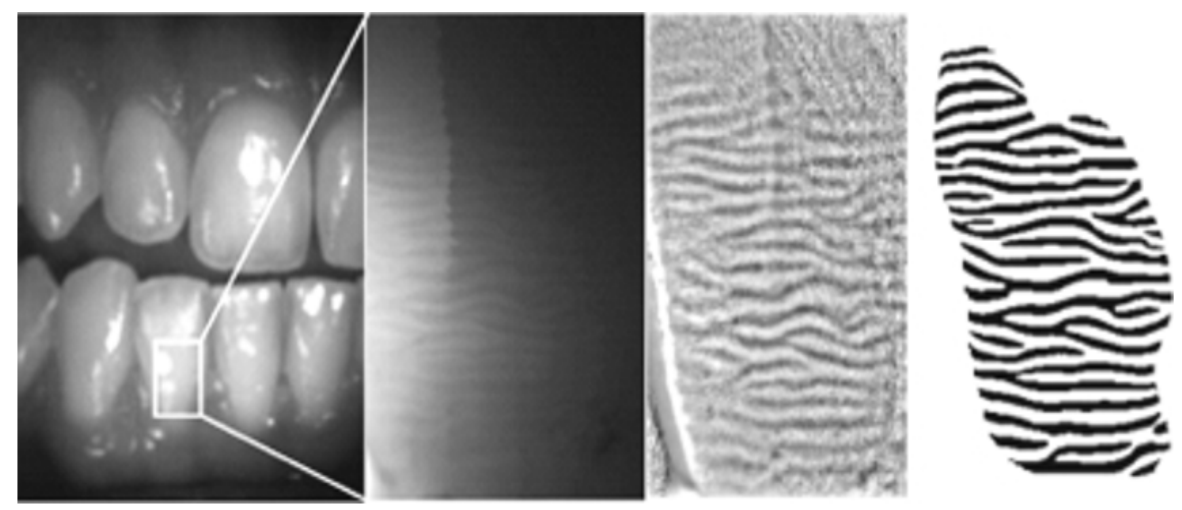

Figure 4. Photomicrograph taken from previous research 9

of the teeth, the enamel print pattern can be observed clearly. ${ }^{9}$ Therefore, there is no question on the reliability of using photomicrograph method in this study.

Another study done by Joshi and Bhosale revealed that tooth prints were special and showed distinct dissimilarity both between the teeth of different individuals and of the same individual. In this study, all tooth print patterns are dissimilar and this is proven by the Source AFIS-1.7.0 software. The software uses certain points called minutiae to compare the similarity or variability of all tooth print patterns and none shows similarity. From the surface of tooth that is being analyzed, the enamel rod end patterns do not have any similarities from all the tooth prints 
collected. This proves that tooth print is very unique and can be used as a relevant and useful tool in forensic personal identification.

The most prominent sub-pattern obtained in this study is the linear-branched followed by the wavy-branched and so on. But Christopher et al. ${ }^{10}$ concluded that in their study the wavy branched sub-pattern was the predominant tooth pattern. The differences of enamel print patterns may be due to the unique deviations in environmental factors surrounding each developing tooth which includes developing tooth bud placement, pressure, temperature and nutrition to the ameloblast cells. Apart from that, genetics might also have a role in determining the type of pattern. ${ }^{3}$ This means that there could be differential movement of the ameloblast during amelogenesis and the environmental factors during different periods of tooth development could change the ameloblasts arrangement. As a result, different enamel print patterns will be observed. But, the role of genetics in the determination of rod end patterns is yet to be understood and need further research to confirm it. ${ }^{11}$

On the other hand, there are many limitations to this study. The enamel surface is frequently subject to wearing either to micro- or macrowearing. Despite the fact that the enamel is the hardest substance in the human body, processes such as abrasion, attrition and erosion wear the outermost layer of enamel rod ends and hence, exposing the underneath layer. This effect on the enamel rod end pattern should be determined by further research. ${ }^{6}$ Secondly, the enamel rods do not cross the whole length of enamel in a straight pattern. Rather, they transverse in undulating and inter-twining paths which give rise to high tensile strength of enamel and the appearance of gnarled enamel and Hunter-Schreger bands. Hence, the enamel rods course is definitely not the same throughout the thickness of enamel. Theoretically, the enamel rod end pattern differs at different thickness of enamel and further studies need to be done to verify this. ${ }^{12}$

In another study by Manjunath and Sivapathasundharam ${ }^{13}$ which reveal that enamel rod end patterns change pattern due to in vivo brushing and it usually takes about 4-6 years to change So, the enamel rod end pattern should be recorded at least every 4 years during its practical application in forensic identification. There is a need for further in vivo study to analyze the effect of abrasion on enamel print patterns and its changes over a period of time for a more accurate application of using enamel print patterns for personal identification and verification. ${ }^{13}$

Tooth prints are specifically unique to an individual tooth but the value of it to be used as a tool in legal science for personal identification depends on its reproduction and permanency. Further studies should be done to access the quality of enamel print patterns. ${ }^{14}$ In conclusion, the enamel print patterns vary in every tooth among individuals and play a significant role in personal identification.

This research has it's own weakness and hence there are few suggestions for further development research. The suggestions based on this research are further research needs to be conducted with larger sample size to increase the accuracy of the result, research also could be widen and deepen by using other teeth such as canine, premolar and molar to compare its accuracy, higher camera resolution and a better controlled lighting background to capture the enamel print pattern more precisely to increase the accuracy and certainty of the enamel print pattern.

\section{CONCLUSION}

The description of enamel print patterns in Deutero Malay sub race based on extracted female permanent maxillary central incisors are different from one another. Every samples has a combination of few sub-patterns, but there is no similarity found. Hence, this method can be used as a possible method for personal identification.

\section{REFERENCES}

1. Sazena S, Sharma P, Gupta N. Experimental studies of forensic odontology to aid in the identification process. J Forensic Dent Sci 2010;2(2):69-76. DOI: 10.4103/09751475.81285.

2. Manjunath K, Sivapathasundhararam B. Saraswathi T. Efficacy of various materials in recording enamel rod endings on tooth surface for personal identification. J Forensic 
Dent Sci 2011;3(2):71-6. DOI: 10.4103/09751475.92148.

3. Deshmukh RA. Need for newer techniques for personal identification. J Forensic Res 2015;6(3):284. DOI: 10.4172/2157$\underline{7145.1000284}$

4. Dahal S, Boaz K, Srikant N. Agrawal NK. Ameloglyphics: A novel appraisal of the enamel structure in identification of an individual. $J$ Inst Medic 2014;36(3):64-7.

5. Kumar GS. Orban's oral histology and embriology. $12^{\text {th }}$ ed. India: Elsiever; 2007. p. 45-74.

6. Prasetyono TOH, Moegni KF. Morphometry of Deutero malay female nose, Medic J Indonesia. 2009;18(3):120-3. DOI: 10.13181/ mji.v18i3.359

7. Joshi P, Ennett GL, Horuk R. Iodination chemokines for use in receptor binding analysis. In: Horuk R, editor. Chemokine receptors. New York: Academic Press; 1997. p. $134-48$.

8. Gupta H, Hardiya S. Study of enamel rod patterns in multiple teeth: A Biometric Analysis. Int J Med Appl Sci 2014;3(4):234-9.

9. Ramenzoni LL, Line SR. Automated biometrics- based personal identification of the HunterSchreger bands of dental enamel. Proc Biol Sci. 2006;273(1590):1155-8. DOI:10.1098/ rspb.2005.3409.

10. Christopher V, Murthy S, Ashwinirani SR, Prasad K, Girish S, Vinit SP. Can dead man tooth do tell tales? Tooth prints in forensic identification. J Forensic Dent Sci. 2017;9(1):47. DOI:10.4103/ jfo.jfds_24_16.

11. Girish H, Murgod S, Hegde RB. Ameloglyphics and predilection of dental caries. J Oral Maxillofac Pathol. 2013;17(2):181-4. DOI:10.4103/0973-029X.119752

12. Manjunath K, Sriram G, Saraswathi T, Sivapathasundharm B. Enamel rod end patterns: A preliminary study using acetate peel technique and automated biometrics. J Forensic Odontol. 2008;1(1):33-6

13. Sivapathasundharam B MK. Analysis of enamel rod end pattern at different levels of enamel and its significance in ameloglyphics. J Forensic Res. 2014;5(4):1. DOI:10.4172/21577145.1000235.

14. Gourav N. The Need for Advanced Techniques in Personal Identification. Res Rev J Pharmacol Toxicol Stud. 2016;4(4):64-9. 